\title{
La inserción del tema del Grial en el Lancelot en prose
}

\section{Rosalba LENDO Universidad Nacional Autónoma de México}

\begin{abstract}
El tema del Grial aparece por primera vez en la novela artúrica francesa en el Conte du Graal (1180-1181) de Chrétien de Troyes. Uno de los episodios clave de esta novela es el de la visita de Perceval al castillo del Rey Pescador, donde asiste a un misterioso cortejo en el que figura una doncella que lleva un magnífico grial (vaso/fuente) de oro. A pesar de su curiosidad, el héroe se abstiene de hacer la pregunta esperada: ¿a quién se sirve con el grial?, pregunta que habría sanado al rey, tullido desde hace muchos años, y devuel to la fertilidad a su reino. Más adelante, cuando Perceval se entera de su fracaso en esta aventura, decide no descansar hasta encontrar nuevamente el castillo del Rey Pescador y preguntar acerca del objeto. A partir de este momento, el Grial se presenta como un objeto de queste (búsqueda), destinado a un héroe específico. Sin embargo, la novela inacabada de Chrétien deja sin resolver el misterio del Grial y deja abiertas una serie de preguntas: ¿qué es el Grial?, ¿cuáles son sus orígenes?, ¿cuál es su destino?, preguntas a las que los autores posteriores trataron de dar una respuesta.
\end{abstract}

Las cuatro Continuaciones del Conte du Graal, redactadas durante las primeras décadas del siglo XIII, plantearon distintas posibilidades de completar la novela de Chrétien, pero fueron sobre todo los ciclos artúricos los que intentaron elucidar de manera definitiva los misterios del Grial, inventándole un pasado y un futuro, $y$ ligando este objeto al origen $y$ al devenir del universo artúrico. Así, el tema del Grial permitió la configuración de los grandes conjuntos novelescos elaborados durante el siglo XIII con el fin de relatar la historia completa del rey Arturo y los caballeros de la Mesa Redonda.

La primera recopilación cíclica, la trilogía atribuida a Robert de Boron, fue realizada a principios del siglo XIII. Su primera parte, la Estoire del Saint Graal (Historia del Santo Grial), relata los orígenes del Grial en la época bíblica. Descrito apenas por Chrétien como algo sagrado, tant sainte chose. el objeto es aquí completamente cristianizado y adquiere una definición y una interpretación precisas. Robert de Boron lo identifica con el cáliz de la 
Última Cena y en el que José de Arimatea recogió la sangre de Cristo después de su crucifixión. Reliquia del misterio de la Eucaristía y testigo de la Pasión, el Grial se convierte para José y los suyos en símbolo de gracia divina. Siguiendo la voluntad de Dios, José instituye el linaje elegido de guardianes del Grial, que comienza con Bron, su cuñado, quien se encargará de llevar la Santa Reliquia a Occidente, a la Gran Bretaña artúrica, y de esperar la llegada de su nieto, Perceval, último guardián. El Merlin, segunda parte de la trilogía, marca la transición entre la época bíblica y la de la caballería artúrica, cuyo más alto símbolo es la Mesa Redonda, institución predestinada para la realización de la aventura del Grial, relato de la última parte del conjunto, el Perceval, donde dicho héroe lleva a buen fin la búsqueda del Grial, realizando así las promesas divinas. El relato culmina con la muerte de Arturo y la destrucción de su reino.

Si la trilogía de Robert de Boron marca la primera etapa en la evolución de los ciclos artúricos, es en el Lancelot-Graal o ciclo de la Vulgata, realizado entre 1215 y 1230 , donde queda definitivamente configurada la historia del Grial: de sus orígenes, de su trayectoria en el universo artúrico y de su desaparición. De dimensiones extraordinarias, el Lancelot-Graal, segundo y más importante ciclo artúrico, fue concebido bajo una triple perspectiva: caballeresca, cortés y religiosa. El conjunto consta de cinco partes, cuyos títulos son muy significativos: Estoire del Saint Graal (Historia del Santo Grial), Merlin y su continuación, Lancelot en prose (Lanzarote en prosa), Queste del Saint Graal (Demanda del Santo Grial) y Mort le Roi Artu (Muerte del rey Arturo). En un principio el ciclo estaba formado por las tres últimas novelas. Redactadas por uno o varios autores, la cuestión está lejos de ser resuelta, éstas se caracterizan por su estrecha relación, que atestigua el riguroso plan que permitió estructurar de manera coherente este primer núcleo. Al conjunto se le agregaron posteriormente y con el fin de completarlo, la Estoire, versión amplificada de la novela de Robert de Boron, el Merlin, del mismo autor, y su continuación, denominada Suite-Vulgate.

El Lancelot en prose, novela de proporciones considerables (nueve volúmenes en la edición de Alexandre Micha'), constituye el núcleo central del ciclo, alrededor del cual éste se fue poco a poco estructurando. A grandes rasgos, el texto relata la historia de Lanzarote, quien, gracias a sus cualidades físicas y morales, a sus grandes hazañas, motivadas por su amor hacia Ginebra, esposa del rey Arturo, se convierte en el mejor caballero. Todo parece perfilarlo como el héroe de la Queste, como el único capaz de llevar a buen fin la

'Lancelot, roman en prose du XI//e siècle. Ed. de Alexandre MichA. París/Ginebra, Droz, 1978-1983. 9 vols. 
más alta aventura, la búsqueda del Santo Grial. Sin embargo, su adulterio con Ginebra lo hará indigno de este honor, que Dios concederá a su hijo Galaad, nuevo héroe de la Queste que sustituye a Perceval en el Lancelot-Graal.

La estrecha relación que liga el Lancelot en prose a la Queste se manifiesta fundamentalmente a través de la inserción del tema del Grial en la primera novela. Desde las primeras páginas, en las que se narra la infancia de Lanzarote, descubrimos que el verdadero nombre del héroe es Galaad, nombre marcado con el signo de elección. Así, desde el principio, el relato se proyecta ya hacia un futuro claramente definido, que va de Lanzarote a su hijo Galaad y del Lancelot en prose a la Queste. A medida que el relato avanza, los lazos que unen a estas dos novelas se vuelven cada vez más evidentes, sobre todo en la última parte del texto, denominada acertadamente por Ferdinand Lot "Preparación para la Queste". ${ }^{2}$ El análisis de algunos de los pasajes más importantes del Lancelot en prose que introducen el tema del Grial, definiendo así la transición a la Queste, constituye el objeto del presente estudio.

El tema del Grial se introduce en la novela de dos maneras distintas. Primero a través de una serie de pasajes que anuncian la llegada del "Buen Caballero" que terminará las aventuras del Grial; se trata de predicciones graduales que se convierten poco a poco en una obsesión, en un llamado continuo a la conquista de la Santa Reliquia, y que sólo culminarán el día que Galaad llegue a la corte de Arturo, escena que marca el inicio de la Queste. Antes de que esto suceda, el Grial, pero esta vez el objeto mismo, entra también en escena de manera progresiva. Ésta es la segunda forma de inserción del tema en el Lancelot en prose.

\section{Los anuncios que preparan la llegada del "Buen Caballero"}

Los anuncios que preparan la llegada del héroe de la Queste aparecen poco a poco en el relato. A medida que se van presentando, se precisan no sólo las cualidades del elegido divino, sino también las hazañas que éste realizará durante su camino hacia la conquista del Grial. Las indicaciones del texto nos hacen suponer que una vez terminada esta búsqueda, culminarán también las aventuras del reino de Logres, la Gran Bretaña artúrica. En efecto, cuando se habla de la Suprema Aventura es siempre en plural: "par cui seront achevees les aventures del saint Graal" ("por él serán terminadas las aventuras del santo Grial"). De esta manera se establece una extraña relación entre las aventu-

\footnotetext{
${ }^{2}$ Cf. Ferdinand LoT, Etude sur le "Lancelot en prose", cap. IV.
} 
ras de Logres y el Grial. En efecto, dichas aventuras, "terribles y peligrosas", se explican por la presencia del Grial, par la force du Graal, en el reino, donde se espera con impaciencia la llegada del caballero que terminará con estos extraños fenómenos. El milagro que tendrá lugar en la Queste, donde Galaad es recibido con honores como "celui que nos atendions achever les aventures del Saint Graal"3 ("aquel que tanto esperábamos para que diera fin a las aventuras del Santo Grial"), tenía que ser revestido de un esplendor particular. Los pasajes del Lancelot en prose que preparan la llegada de Galaad fueron concebidos con este fin. Pero su función consiste también en designar a los caballeros, y especialmente a Lanzarote, que serán eliminados de la Suprema Aventura.

Uno de estos pasajes es la escena donde maître Hélie interpreta el sueño de Galehaut, anunciándole que el leopardo que vio, y que representa a Lanzarote, no es quien terminará la aventura del Grial, pues habrá un caballero que lo superará. Esta primera predicción nos ofrece ya algunas indicaciones sobre el futuro héroe: "cil qui achevera les aventures de Bretaigne sera li mieldres chevaliers de tot le monde et aemplira le deerain siege de la Table Reonde, et cil a en escripture la senefiance de lion"4 ("aquel que pondrá fin a las aventuras de Bretaña será el mejor caballero del mundo, ocupará el Asiento Vacío de la Mesa Redonda, y ha sido designado con el símbolo del león").

Lanzarote ha perdido toda oportunidad de ser elegido, anuncia maître Hélie a Galehaut, pues una de las condiciones para ello es que el caballero "soit de sa nativité jusqu'a sa mort virges et chastes"s ("sea casto y virgen durante toda su vida"). Sin embargo, predice Hélie, es él quien engendrará al león: "del lieupart orgueillos et de la ligne de Jherusalem istroit li lions redotés desor totes autres bestes"6 ("del leopardo orgulloso y del linaje de Jerusalén saldrá el león, el más temido de todos los animales”).

En el episodio de la Carreta, Lanzarote llega al Santo Cementerio y descubre la tumba ardiente de Siméon (padre de Moyse y sobrino de José de Arimatea), quien se consume eternamente en el fuego por un pecado que cometió. El caballero trata de levantar la lápida de la tumba, pero las flamas que la rodean se lo impiden: esta aventura no es para él, sino para aquel que pondrá fin a las aventuras de Bretaña, le advierte Siméon desde la tumba, y le revela igualmente que la llegada del Buen Caballero se acerca y que éste será de su linaje. ${ }^{7}$

${ }^{3}$ La Queste del Saint Graal, ed. de Albert PaUPHILET, p. 7.

${ }^{4}$ Lancelot en prose..., ed. de A. Мicha, t. I, cap. IV, $\$ 34$.

${ }^{5}$ Ibid., t. I, cap. IV, $\$ 36$.

${ }^{6}$ Ibid., t. 1, cap. IV, $\$ 41$.

${ }^{7}$ Ibid., t. II, cap. XXXVII, $\$ 40$. 
Más adelante, Gauvain, acompañado por diez caballeros, parte de la corte en busca de Lanzarote. En el camino encuentran a Eliezer (hijo del rey Pellés, guardián del Grial), quien les presenta los dos trozos de la espada sangrante para ver si alguno de ellos logra unirlos. La espada fue rota cuando un sarraceno hirió con ella a José de Arimatea, quien predijo en aquel entonces: "Ha! espee, jamés ne seras soldee devant que cil te tendra a ses mains qui les hautes aventures del Graal devra assomer" (" $i \mathrm{Ha}$ ! espada, no podrás ser soldada hasta que no te tenga en sus manos aquel que acabará las aventuras del Grial").

Gauvain y sus compañeros tratan en vano de realizar la hazaña: el elegido no se encuentra entre ellos. En efecto, todos estos caballeros serán eliminados, en la Queste, de la aventura del Grial, pues no reúnen las cualidades necesarias para llevar a cabo tan alta empresa.

Siguiendo la búsqueda de Lanzarote, Gauvain y Hector llegan a un cementerio, donde descubren una tumba con una inscripción que anuncia que las aventuras de ese lugar sólo podrán ser terminadas por "li chatis chevaliers qui par sa maleurose luxure a perdu a achever les merveilloses aventures del Graal"9 ("el pobre caballero que, debido a su terrible lujuria, perdió el derecho de acabar las maravillosas aventuras del Grial").

Otra inscripción precisa la identidad de este caballero: "li fils a la roine dolerose" ("el hijo de la reina dolorosa"), es decir, Lanzarote, cuya madre, se relata al principio de la novela, sufrió tanto con la muerte de su esposo y la pérdida de su hijo, raptado por la Dama del Lago, que fue llamada desde entonces la roine dolerose.

Los caballeros no toman en cuenta la advertencia y son atacados por las espadas que custodian las tumbas. Después se marchan del cementerio sin comprender el significado de las revelaciones. Sólo la reina Ginebra podrá descubrirlo cuando, a su regreso a la corte, Gauvain cuenta las aventuras que le acontecieron.

A medida que el relato avanza, las predicciones sobre la llegada del héroe del Grial se vuelven más claras, pues su nacimiento se acerca. Al principio del episodio de la visita de Lanzarote a Corbenic, el castillo del Grial, el caballero llega a un cementerio donde encuentra la siguiente inscripción en una tumba: "Ja ceste tombe ne sera levee devant que li lieparz y mestra main, de qui li granz lions doit issir, et cil la levera legierement, et lors sera engendrez li granz lions en la belle fille au roi de la Terre Foraine"10 "Esta tumba sólo podrá ser abierta por el leopardo, de quien saldrá el gran león; sólo él podrá le-

${ }^{8}$ Ibid., t. II, cap. LXI, $\$ 31$.

${ }^{9}$ Ibid., t. II, cap. LXV, $\$ 24$

${ }^{10} \mathrm{Ibid}$., t. IV, cap. LXXVIII, $\$ 46$. 
vantar la lápida sin ninguna dificultad, y entonces será engendrado el gran león en la hija del rey de la Terre Foraine").

Lanzarote pasa con éxito la prueba pero no logra comprender el significado de la oscura predicción. Sólo Pellés, rey de la Terre Foraine, reconocerá al caballero como el único digno de engendrar al elegido divino: "Dont je sui touz aseur que par vos o par chose qui de vos istra sera cil païs delivrez des estranges aventures qui y aviennent jor et nuit"ll "Estoy seguro que por vos o por alguien que nacerá de vos será esta tierra liberada de las extrañas aventuras que acontecen día y noche").

Sin embargo, Lanzarote no entiende el sentido de sus palabras, y, víctima de los planes del rey y de los hechizos de Brisane, tendrá relaciones con la hija de Pellés, creyendo que se trata de Ginebra, y concebirá a Galaad, héroe de muy alto rango pues pertenece al linaje de los guardianes del Grial por el lado materno y al del rey David por el paterno. Su nombre es revelado ya en este episodio, donde el autor nos remite directamente a la Queste: "Galaaz, li virges, li tres bons chevaliers, cil qui les aventures del Saint Graal mist a fin et s'asit el perilleus siege de la Table Reonde ou onques chevaliers ne s'estoit assis qui ne fust morz [...] si com il devise apertement en la Queste del Graal"/2 ("Galaad, el virgen, el buen caballero que terminó las aventuras del Grial y se sentó en el Asiento Peligroso de la Mesa Redonda, donde ningún otro cabaIlero pudo sentarse antes sin perder la vida, asi como lo cuenta detalladamente la Queste del Graal").

Las predicciones que aparecen después en el Lancelot en prose repiten lo que ya ha sido anunciado. Sólo nos limitaremos a señalar dos que nos parecen importantes, ya que en ellas Lanzarote toma verdaderamente conciencia del motivo de su futuro fracaso. La primera se encuentra en el episodio donde Ginebra descubre, a través del relato de las aventuras de Gauvain, que Lanzarote ha perdido, por su causa, la oportunidad de conquistar el Grial. Al ver su sufrimiento, sus remordimientos, el caballero trata de reconfortarla afirmándole que no se arrepiente de su gran amor. Con un convencimiento total, Lanzarote declara que, sin este amor, principio de virtud caballeresca, no habría sido capaz de realizar ninguna hazaña, y renuncia sin arrepentimiento a la gloria del Grial a cambio de la dicha procurada por el amor. ${ }^{13} \mathrm{En}$ otro diálogo, manifiesta, una vez más, su visión de un mundo donde la proeza no tiene otra fuente de inspiración y otra razón de ser que el amor. ${ }^{14}$

"Ibid., t. IV, cap. LXXVIII, $\$ 49$.

12 Ibid., t. IV, cap. LXXVIII, $\$ 57$.

13 Ibid., t. v, cap. LXXXV, $\$ \$ 1-2$.

${ }^{14}$ Ibid., t. IV, cap. LXXXIV, $\$ 47$. 
La segunda predicción no es más que una confirmación de la primera y una severa denuncia del pecado de Lanzarote. En el Bosque Peligroso el caballero descubre una fuente hirviente en la que se encuentra la cabeza de su abuelo; logra retirar la cabeza, pero no puede enfriar la fuente. Al lado de ésta, una inscripción anuncia lo siguiente: "Ja ceste chalor n'estaindra devant que li mieldres chevaliers del monde y vendra, cil par cui virginitez ne sera corrompue ne malmise. Mais lors faudra ceste chalor pour ce qu' an lui n'avra eu eschaufement de luxure"15 "Este calor sólo cesará cuando venga el mejor caballero del mundo, cuya virginidad no será corrompida; él logrará acabar con este calor porque en él no habrá lujuria").

Su pecado de lujuria, quemadura de cuerpo y alma, es lo que le impide enfriar la fuente, como le impidió también acercarse a la tumba ardiente de Siméon, tal como se lo explica un ermitaño. ${ }^{16}$

Podemos pues constatar, a través de estos anuncios, que la condena de Lanzarote, pronunciada desde el pasaje en el que maître Hélie interpreta el sueño de Galehaut, no cesará de repetirse a lo largo del relato, como un constante eco cuyo objetivo es disuadirnos de la idea de que, aun siendo el mejor caballero, él pueda ser el elegido divino. Desde el momento en que Lanzarote es armado caballero, su ascenso hacia la perfección inicia y lo lleva poco a poco a la cumbre de la gloria. Sin embargo, a medida que se va definiendo la aventura del Grial como algo más espiritual que terrenal, el máximo representante de la "caballería terrenal" quedará definitivamente descartado por su condición de pecador.

El análisis de algunas de las más importantes predicciones sobre Grial, en el Lancelot en prose, nos permite definir sus características principales. Su objetivo parece ser anunciar la futura llegada del "Buen Caballero" que terminará las aventuras del Grial, precisar sus cualidades y preparar algunas de las aventuras que le han sido predestinadas y que serán relatadas en la Queste. La función esencial de estas predicciones es pues develar poco a poco el futuro del relato. Así, el lector puede percibir, en el inmenso laberinto de aventuras que constituye el Lancelot en prose, una especie de camino que se va definiendo y en el que se va perfilando el fin de la historia artúrica. Como en las demás novelas cíclicas, los anuncios que figuran en el Lancelot en prose favorecen la cohesión entre las diferentes partes del ciclo. Son ellos los que marcan la línea directriz del relato, ofreciendo al lector una visión global de una historia que se dirige hacia un futuro preestablecido, hacia un doble desenlace: el fin de la aventura del Grial y, consecuentemente, el del reino artúrico.

15 Ibid., t. v, cap. XCIII, $\$ 6$.

${ }^{16}$ Ibid., t. v, cap. XCIII, $\$ 17$. 
Sin embargo, los anuncios no resuelven una cuestión fundamental respecto a la última y más importante aventura del universo artúrico: ¿qué significa en realidad descubrir el Grial? El lector tendrá que buscar la respuesta al principio de la Queste, en la escena que relata la aparición de la Santa Reliquia en la corte de Arturo: una gran claridad invadió entonces el palacio, y los caballeros que estaban allí reunidos en la Mesa Redonda quedaron como iluminados por la gracia del Espíritu Santo. El Grial, sin ser sostenido por nadie y cubierto con un velo blanco, entró en la sala donde éstos se encontraban, para colmarlos con los más exquisitos manjares y luego desaparecer. Maravillados por el prodigio y deseosos de contemplar más abiertamente el Santo Vaso, los caballeros deciden partir en su búsqueda. Todos participarán en ella pero sólo tres, Bohort, Perceval y Galaad, lograrán terminarla al final de la Queste, y sólo Galaad podrá contemplar el interior del Grial y descubrir los misterios divinos encerrados en él: "ce que langue ne porroit descrire ne cuer penser"17 ("lo que ninguna lengua podría describir y ningún corazón pensar"). La búsqueda del Grial representa pues el esfuerzo del "Buen Caballero" para encontrar, gracias a la ayuda de Dios, quien lo ha elegido, la Santa Reliquia, tomar posesión de ella y acceder a la mística contemplación.

\section{Las visitas de los caballeros a Corbenic}

A medida que el relato avanza y que la progresión hacia la Queste se vuelve más clara, el Grial deja de ser una simple alusión para convertirse en una realidad. El objeto de la futura búsqueda es finalmente mostrado a los caballeros que llegan a Corbenic, pero permanece aún envuelto en el más profundo misterio. Como en el caso de las predicciones, aquí también asistimos a un ascenso gradual hacia el conocimiento del Grial, ascenso que dependerá de las cualidades morales de cada caballero. Así, la visita a Corbenic, el Palacio Aventuroso, se presenta como un pasaje fundamental para los futuros participantes en la búsqueda. Su comportamiento durante esta visita definirá el lugar que ocuparán.

Gauvain es el primer visitante. Coleccionista de éxitos en lo que se refiere a hazañas caballerescas y conquistas amorosas, pero de fracasos en las aventuras relacionadas con el Grial, Gauvain, quien no logró unir las dos partes de la espada de Eliezer, como lo hemos mencionado, fracasará también en las aventuras de Corbenic. En busca de un lugar para pasar la noche, llega accidental-

${ }^{17}$ La Queste..., ed. de A. PAUPHILET, p. 278. 
mente al castillo y trata en vano de pasar la primera prueba, sacar a una doncella de una cuba de agua hirviente; ésta le advierte entonces: "Ha! sire chevaliers, failli avéz. Ore poés dire seurement que ja de cest chastel ne partirois sans honte avoir" ${ }^{18}$ ("¡Ha! señor caballero, habéis fracasado. Ahora podéis estar seguro de que no os marçharéis de este castillo sin ser deshonrado").

En el palacio, Gauvain es recibido por el rey Pellés y asiste a una serie de sucesos extraordinarios: una paloma que lleva en el pico un incensario entra por la ventana; la sala se llena entonces de los más suaves olores y las personas que allí se encuentran comienzan a rezar. Gauvain las observa. En ese preciso instante, el Grial, llevado por la hija del rey Pellés, atraviesa la sala. Cautivado por la belleza de la joven, el caballero no presta mayor atención al cáliz. Mientras los asistentes se arrodillan ante él, Gauvain sólo contempla a la doncella, sin imaginar, ni por un sólo instante, que se encuentra frente a un objeto sagrado: "Apres regarde la pucele si se merveille plus assés de sa bialté que del vaissel, kar onques mes en vit il feme qui de bialté s'apareillast a ceste : si muse a li si durement qu'a autre rien ne pense"19 ("Mira a la doncella, más maravillado por su hermosura que por el vaso, pues nunca vio mujer de belleza semejante: la mira tanto que no puede pensar en otra cosa").

Más conmovido por la hermosura de la doncella que por las cosas divinas, Gauvain es presentado como un ser cerrado a la gracia e incapaz de elevarse a la plegaria y a la contemplación de la Santa Reliquia. Su actitud tendrá terribles consecuencias: privado de los manjares que el Grial va distribuyendo a su paso, Gauvain se queda solo, una vez que los asistentes se marchan, y será testigo, durante toda la noche, de una serie de sucesos maravillosos que tendrán lugar en el palacio. Sometido a terribles visiones y tormentos, el caballero logra ver una vez más el Grial y comprende entonces que se trata de algo sagrado. Demasiado tarde, pues ha perdido ya toda oportunidad de acercarse a él. Una parálisis momentánea, que no es más que un castigo divino, le impide hacerlo. A la mañana siguiente, Gauvain amanece fuera del castillo, amarrado a la carreta de la ignominia. Un ermitaño le explicará el significado del misterioso cáliz y de lo que le aconteció en Corbenic: "Certes, fet il, ce fu li Sains Graas ou li sains sancs Nostre Seignor fu espandus et recueillis. Et quant vos ne fustes humelians et simples, bien vos doit estre ses pains veez et si fu il: ce veistes vos bien, quant tuit furent servi et vos y fustes obliez"20 "Ciertamente, era el Santo Grial, en el que fue depositada la santa sangre de Nuestro Señor. Y como no mos-

\footnotetext{
${ }^{18}$ Lancelot en prose..., ed. de A. MichA, t. II, cap. LXVI, $\$ 5$.

${ }^{19}$ Ibid., t. II, cap. LXVI, $\$ 13$.

${ }^{20}$ Ibid., t. Il, cap. LXVI, \$34.
} 
trasteis ninguna humildad, su gracia os fue negada. Así, cuando todos fueron servidos, vos fuisteis olvidado").

El segundo caballero que llega a Corbenic es Lanzarote. La primera diferencia que observamos aqui es que él no llega al castillo del Grial por accidente, sino que es conducido por una doncella. Tras pasar con éxito la primera prueba: retirar a la doncella de la cuba, entra en un cementerio donde realiza algunas aventuras que le estaban reservadas. Más tarde asiste al cortejo del Grial. Su comportamiento es muy distinto al de Gauvain. Al ver que los asistentes comienzan sus plegarias, Lanzarote hace lo mismo. Y aunque su reacción pueda parecer una simple imitación dictada por reglas de cortesía, el caballero está lejos de manifestar la apatía de Gauvain. Desgraciadamente, al igual que éste, no puede dejar de admirar la belleza de la doncella que lleva el cáliz, belleza que, de cualquier manera, le parece inferior a la de la reina Ginebra. Pero Lanzarote contempla también con admiración el cáliz, presintiendo que se trata de algo sagrado: "si li est avis, et bien le croit, que ce soit sainte chose et digne; si conmança les mains a joindre et a encliner le piteusement"2l ("le parece que es un objeto sagrado y digno; entonces junta las manos y se inclina piadosamente").

Este discreto gesto de devoción, que lo hará digno de compartir los alimentos del Grial junto con los demás asistentes, marca ya una progresión. A diferencia de Gauvain, Lanzarote tiene una vaga intuición de lo divino y una cierta disposición hacia lo espiritual, aunque su actitud sea esencialmente profana. En efecto, el caballero no puede evitar comparar la belleza de la doncella con la de Ginebra, y cuando el rey Pellés le pregunta qué opina del cáliz que ésta lleva, le responde: "Il me samble que de damoisele en vi onques si bele; de dame ne die je mie"22 ("Me parece que nunca he visto una doncella tan hermosa; de una dama no puedo decir lo mismo").

La tercera visita a Corbenic es la de Bohort. Su reacción al ver el cáliz es totalmente distinta a la de Gauvain y Lanzarote. Verdaderamente conmovido, Bohort no tiene la intuición sino la certeza de encontrarse frente al Grial: "Et quant Boorz vit le Saint Vessel, si l'aoura moult doucement et l'anclina o plors et o larmes, car bien pensoit que c'estoit li Sainz Graal dont il avoit mainte foiz oï parler" ${ }^{23}$ ("Cuando Bohort vio el Santo Vaso, lo adoró con gran devoción y, con lágrimas en los ojos, se inclinó ante él, pues sabía bien que era el Santo Grial, del que tantas veces había oído hablar").

${ }^{21}$ Ibid., t. IV, cap. LXXXVill, $\$ 51$.

22 Ibid., t. IV, cap. LXXVIII, $\$ 52$.

23 Ibid., t. IV, cap. LXXXI, § 12. 
Su actitud es sincera, natural, y no simple imitación. Al contemplar el Grial, Bohort se siente invadido por una emoción y una fe profundas. De los tres caballeros, él es, sin duda alguna, el más digno de la gracia del Grial.

La segunda visita de Bohort a Corbenic confirma el lugar privilegiado que el caballero tendrá en la búsqueda del Grial. El episodio relata las pruebas que pasará con éxito en el palacio, hasta el momento en que finalmente logra acercarse a la habitación donde se encuentra la Santa Reliquia, pero no puede penetrar en el recinto, pues la entrada está custodiada por una espada. De cualquier manera, Bohort será el único que podrá ver la luz que emana del cáliz en el momento en que un hombre vestido de obispo retira el velo de seda que lo cubre. Esto será todo lo que podrá ver, pues perderá la vista hasta el amanecer.

Las tres etapas hacia el conocimiento del Grial, representadas a través de estas tres visitas, marcan tres comportamientos distintos que van en ascenso: de la indiferencia absoluta de Gauvain frente al objeto sagrado, pasamos a la intuición de lo divino y a una cierta devoción por parte de Lanzarote, para culminar con la certeza, la emoción y la fe sinceras de Bohort. Estas tres actitudes, que muestran claramente la disposición de cada caballero para elevarse a lo sagrado y recibir la gracia de Dios, definirán el lugar que cada uno ocupará en la demanda del Grial. Pero el éxito o el fracaso en Corbenic no es en realidad más que la consecuencia de la vida que ha llevado cada caballero y que ha decidido su futuro.

Evidentemente, Gauvain ha perdido toda oportunidad de conquistar el Grial. Su visita a Corbenic sólo sirve para confirmar que el caballero se ha alejado por completo del camino del Señor. Si su proeza pudo salvarlo de un triste fin en el Palacio Aventuroso, no logró impedir que fuera deshonrado y amarrado en la carreta de la infamia. La proeza no es suficiente cuando se trata de una aventura que ya no es de carácter terrenal sino espiritual, y que sólo podrá ser llevada a cabo por aquellos que estén limpios de todo pecado, tal como lo advierte un ermitaño en la Queste: "nus en si haut service ne doit entrer devant qu'il soit netoiez et espurgiez de totes vilanies et de toz pechiés mortex. Car ceste Queste n'est mie queste de terriennes choses, ainz doit estre li encerchemenz des grans secrez et des privetez Nostre Seignor"24 ("nadie debe entrar en un servicio tan alto sin estar limpio y purgado de todas las bajezas y de todos los pecados mortales: esta Demanda no es búsqueda de cosas terrenales, sino que debe ser persecución de los grandes secretos y misterios de Nuestro Señor"). ${ }^{25}$

${ }^{24}$ La Queste..., ed. de A. Pauphilet, p. 19.

${ }^{25}$ Demanda del Santo Graal, p. 46. 
Condenado por sus múltiples pecados, por su apego a lo terrenal, Gauvain será uno de los descalificados en la Queste, donde, herido de gravedad, abandona la búsqueda del Grial y desaparece del relato mismo.

Lancelot será también descalificado. A pesar de haber mostrado cierta capacidad para elevarse a lo espiritual, su amor culpable le impedirá, en la Queste, descubrir los misterios divinos. Sin embargo, su arrepentimiento y sus grandes méritos serán recompensados por Dios con una visión parcial de la Santa Reliquia.

El primer lugar de esta jerarquía lo ocupa Bohort, quien, tras haber librado con éxito las duras pruebas de Corbenic y haber logrado acercarse al Grial, es ya un iniciado. Caballero de vida intachable, que sólo cometió, involuntariamente, un pecado de carne, Bohort, quien trató desde entonces de enmendarse y alejarse de la tentación, se perfila ya como un héroe de la búsqueda. Sólo a él le será concedido el derecho de sentarse, en la Mesa Redonda, a la izquierda del Asiento Peligroso, el de Galaad (a la derecha se sentará Perceval, que es virgen), y de compartir con estos dos caballeros la gloria de pertenecer al grupo de los elegidos.

El análisis que hemos realizado nos permite observar que, a partir del momento en que el tema del Grial se incorpora al relato, percibimos un tono cada vez más religioso, es decir, una clara transición a la Queste. En efecto, los valores corteses que habían sido exaltados a lo largo de la novela a través de la figura de Lanzarote, amante de Ginebra, serán cuestionados, pues se convierten en un impedimento para la realización de la más alta aventura. El amor de Lanzarote, fuente de virtud caballeresca, de proezas y hazañas, es denunciado como pecado de lujuria. La introducción del nuevo ideal caballeresco, que se manifiesta claramente en el Lancelot en Prose a través del personaje de Bohort, alcanzará, en la Queste, su máxima perfección en la figura de Galaad. Así, la pureza de cuerpo y alma se convierte en una condición esencial para ser buen cabaliero y en una necesidad para aquel que quiera terminar la aventura del Grial. La idea será claramente expuesta en la Queste, donde los valores cristianos desplazan a los corteses, y la fin amor, encarnada en Lanzarote, será sustituida por el amor a Dios, nuevo ideal encarnado en Galaad.

Sin embargo, la contradicción, en el Lancelot en prose, entre estos dos ideales, el cortés y el religioso, señalada por la crítica desde hace ya mucho tiempo, no es más que aparente, como lo han demostrado Alexandre Micha y Jean Frappier. ${ }^{26}$ En efecto, aunque el tema de la novela sea esencialmente

${ }^{26}$ A. MICHA, Essais sur le cycle du "Lancelot en prose", cap. VIII; Jean FrAPPIER, "Le Graal et la Chevalerie", en Autour du Graal. 
profano, la historia de amor de Lanzarote y Ginebra, el tono religioso está presente a lo largo de todo el relato, acentuándose más al final. No se trata pues de un cambio radical de tono, sino, como Micha lo señaló, de un "crescendo dans une même tonalité". ${ }^{27}$

Desde la primera página del Lancelot en prose, cuando nos enteramos del verdadero nombre de Lanzarote: Galaad, ${ }^{28}$ se perfila ya uno de los elementos fundamentales del ciclo, la filiación entre Lanzarote y Galaad. Más adelante, en el episodio de la concepción de Galaad, el autor explica que el nombre que Lanzarote perdió por su lujuria, par eschaufement de luxure, fue recuperado por su hijo, gracias a su castidad, par atenance de char. ${ }^{29}$ De esta manera se define una clara oposición entre la lujuria del padre y la pureza del hijo. Sin embrago, como maitre Hélie lo predice, sólo el leopardo podrá engendrar al león, es decir que de la más alta manifestación de la "caballería terrenal" surgirá la "caballería celestial". Así, los dos ideales, el cortés y el religioso, que, aparentemente contradictorios, parecían oponerse al interior de la novela, constituyen en realidad la verdadera unidad no sólo del Lancelot en prose, sino de todo el ciclo Lancelot-Graal, cuyo significado moral se manifiesta a través de este doble espíritu.

Fue, sin duda alguna, en la literatura del Grial donde cristalizaron las más altas aspiraciones de la clase feudal, que vio en la caballería artúrica su imagen ideal, la de una "caballería celestial", suprema consagración de la "caballería terrenal", que logra acceder, mediante la perfección, a la revelación mística, a la gracia.

\section{Bibliografía}

BAUMGARTNER, Emmanuèle, "L'écriture romanesque et son modèle scriptuaire: écriture et reécriture du Graal", en De l'Histoire de Troie au Livre du Graal. Le temps, le récit (XIle-XIIle siècles). Orléans, Paradigme, 1994.

BAUMGARTNER, Emmanuèle, "Le Graal, le temps: les enjeux d'un motif", en Le Temps, sa mesure et sa perception au Moyen Age. Actes de Colloque d'Orléans (avril 1991). Caen, Paradigme, 1992, pp. 9-17.

\footnotetext{
${ }^{27}$ A. Micha, op. cit., p. 170.

${ }^{28}$ Lancelot en prose..., ed. de A. MiCHA, t. VIII, cap. I, $\$ 1$.

${ }^{29}$ Ibid., t. IV, cap. LXXXVIII, \$ 58.
} 
BAUMGARTNER, Emmanuèle, "Le Lancelot et la Queste", en L'arbre et le pain. Essai sur la Queste del Saint Graal. París, Société d'Edition d'Enseignement Supérieur, pp. 11-21.

Baumgartner, Emmanuèle, Le récit médiéval. París, Hachette, 1995.

BAUMGARTNER, Emmanuèle, "Temps linéaire, temps circulaire et écriture romanesque (XIIe et XIIIe siècles)", en Le Temps et la Durée dans la littérature au Moyen Age et à la Renaissance. París, Nizet, 1986, pp. 7-21.

Chrétien de Troyes, Le Conte du Graal (Perceval). Ed. de F. LECOY, Les romans de Chrétien de Troyes, t. VI. París, Champion, 1981.

Demanda del Santo Graal. Trad. de C. Alvar. Madrid, Editora Nacional, 1982.

FRAPPIER, Jean, Etude sur la "Mort le Roi Artu", roman du XIIIe siècle. París, Droz, 1936; 3a. ed., Ginebra, 1972.

FraPPIER, Jean, "Le Graal et la Chevalerie", en Autour du Graal, Ginebra, Droz, 1977.

Lancelot, roman en prose du XIIIe siècle. Ed. de Alexandre MiCHA. París/ Ginebra, Droz, 1978-1983. 9 vols.

La Queste del Saint Graal. Ed. de Albert PAuPHILET. Paris, Champion, 1923 ; reimpr. 1984.

LOT-Borodine, Myrrha, "Les grands secrets du Saint-Graal dans la Queste du pseudo Map", en R. NELLI, ed., Lumière du Graal. Etudes et textes. Ginebra, Slatkine, 1977, pp. 151-174.

LOT, Ferdinand, Etude sur le "Lancelot en prose". París, Champion, 1918; reimpr. 1954.

MiCHA, Alexandre, Essais sur le cycle du "Lancelot en prose". Ginebra, 1980. 
Pauphilet, Albert, Etude sur la "Queste del Saint Graal". París, Champion, 1921; reimpr. 1980.

Robert de Boron, Le Roman de l'Estoire dou Graal. Ed. de William A. NitzE. París, Champion, 1927.

Robert de Boron, Merlin, roman en prose du XIIle siècle. Ed. de Alexandre MiCHA. París/Ginebra, Droz, 1980.

STANESCO, Michel y Michel ZINK, Histoire européenne du roman médiéval. París, Presses Universitaires de France, 1992. 